\title{
SOBRE O "POLÍTICO": com Schmitt e apesar de Schmitt ${ }^{1}$
}

\author{
Benjamin Arditi*
}

\begin{abstract}
Uma observação padrão na literatura é o tratamento dado por Schmitt às oscilações políticas entre a nostalgia por um Estado forte da era vestfaliana e uma descrição lúcida do novo cenário político estatal e não-estatal. Menos óbvio é que essas tensões não impedem possibilidades mais interessantes do seu trabalho. Para encontrá-las, é preciso preparar-se para pensar com e a despeito de Schmitt, seja navegando através de sua teoria do político, sem endossar todas as consequências que ele extrai delas, ou tomando sua reflexão em algumas direções que ele não previu, ou não desejou percorrer. Eu examino algumas das tensões - a natureza do vínculo entre guerra e política, o status de inimigos, a justificativa moral da excelência da ordem - e uso sua distinção entre a política e o político - talvez seu discernimento mais original - para desenvolver o tema da dupla inscrição do político.

Palavras-chave: política, político, pós-liberalismo, Carl Schmitt, resistências.
\end{abstract}

INTRODUÇÃO - inimizade, guerra, intensidade

Bobbio, certa vez, formulou uma definição mínima de política, caracterizando-a como a atividade de agregar e defender amigos, dispersar inimigos e lutar contra eles (1982, p.1247-1248). Sabemos que o instigador dessa definição é Carl Schmitt, embora seus críticos, muitas vezes, tenham interpretado equivocadamente a referência à inimizade. $\mathrm{O}$ argumento mais habitual é o de que a oposição entre amigo e inimigo constitui o código básico do político e que tal oposição pode levar à situação extrema de guerra. Se Schmitt estetiza a violência e, no final das contas, glorifica a guerra e a morte, isso talvez explique por que

* Doutor em Teoria Política. Professor de Ciência Política na Faculdade de Ciências Políticas e Sociais da Universidade Nacional Autônoma do México - UNAM.

UNAM - Programa de Posgrado - Facultad de Ciencias Politicas y Sociales - Ortega, 14 - Colonia del Carmen Coyoacan. Coyoacan 04000 - Mexico DF - Mexico. barditi@unam.mx

${ }^{1}$ Uma versão anterior foi publicada em inglês na revista Telos, n.142, Primavera de 2008, p.7-28. Agradeço a quatro leitores cuidadosos de Schmitt, Javier Franzé, David Pan, Gabriella Slomp e Kam Shapiro, pelos comentários sobre uma versão preliminar deste artigo. Suas várias e excelentes observacões detectaram pontos fracos que eu não teria percebido sem sua perspicácia para detalhes. parte do debate sobre O Conceito do Político girou em torno do status do inimigo. O pensamento dele seria belicoso e contrário ao ethos político democrático e pluralista dominante no Ocidente.

Existe alguma verdade nessa acusação, assim como na suspeita de que, para ele, o verdadeiro objeto da política é o Estado. Schmitt tenta evitar subscrever a realidade conflitual do político sob o domínio da guerra, pelo apoio à última como uma condição prévia e possibilidade real para a primeira. Contudo ele destaca as oposições amigo-inimigo como as mais intensas, porque elas sozinhas são capazes de conduzir à guerra. Se oposições étnicas ou de outra natureza conduzem à guerra, é porque elas já deixaram de ser meramente econômicas, étnicas, etc., e se tornaram políticas, pelo fato de adquirirem a intensidade necessária para agrupar pessoas como amigas e inimigas.

Derrida mostrou que o foco de Schmitt sobre a intensidade introduz um telos inesperado em seu conceito do político: a guerra torna-se a essência e não a pré-condição do político (Derrida, 1997, p. 131-132, 139). Isso porque, se a paz abso- 
luta, ou a total ausência de conflito, for colocada numa extremidade do espectro e a guerra no outro, a intensidade de uma oposição aumentará à medida que nos afastemos da paz. As oposições políticas - aquelas estruturadas em torno da relação amigo-inimigo - são impensáveis no caso de conflito zero, porque, nesse caso, não haveria inimizade e, portanto, nenhuma possibilidade de agrupar as pessoas como amigas ou inimigas. Entretanto, uma vez que você se afasta da pura estase, o político pode estar localizado em qualquer nível de intensidade. O problema é que, se oposições econômicas, étnicas, religiosas e de outra natureza também fizerem parte desse espectro, o que é que torna as oposições políticas tão especiais? Schmitt afirma simplesmente que elas são as mais intensas de todas. Mas a medida da intensidade é notoriamente ilusória ou falsa e, se a intensidade - logo, a natureza política - de uma oposição aumenta na medida em que ela se aproxima da guerra, então ela se tornaria a quintessência do político, em vez de ser a manifestação extrema ou excepcional do político. Naturalmente, isso contradiz o desejo de Schmitt de evitar o político e a guerra. A solução mais simples é manter a guerra como uma possibilidade real - como a possibilidade mais extrema e bandonar o critério de intensidade como um meio de distinguir as oposições políticas de outras.

Uma segunda maneira de tratar essa questão é verificar qual o significado que Schmitt teria atribuído à palavra guerra. É óbvio que ele a pensa no sentido estrito de confrontos que envolvem perda de vidas: $\mathrm{o}$ inimigo representa uma ameaça existencial, e isso nos autoriza a lutar e a matá-lo em nome de razões políticas (Schmitt 1996a, p. 32-33, 48-49). ${ }^{2}$ Em parte, isso é assim porque ele buscou sua inspiração no sistema de Estado vestfaliano, em que a política era a alta política de assuntos interestatais, e a guerra um acessório regular. Mas sabemos que Schmitt compreende a possibilidade da guerra como uma pressuposição do político, e não como seu conteúdo ou alvo (p. 34), e define o inimigo político como hostis em vez

${ }^{2}$ Vide também a versão brasileira de $O$ conceito do político traduzida por Alvaro L. M. Valls. Petrópolis: Vozes, 1992. de inimicus. O foco na hostilidade mútua que atua nas oposições políticas é útil na medida em que nos permite falar de uma dupla conexão entre a "guerra" e "o político": a guerra é a manifestação extrema de uma disposição hostil, mas a hostilidade pode ou não levar a batalhas verdadeiras e ao concomitante derramamento de sangue. Essa pode ser uma maneira peculiar de ver a guerra, mas não por isso se trata de uma visão incomum. Por exemplo, pode-se encontrá-la em uma passagem do Leviathan em que Hobbes diz que:

Warre consisteth not in Battell only, or the act of fighting, but in a tract of time, wherein the Will to contend by Battell is sufficiently known (...) So the nature of War, consisteth not in actual fighting; but in the known disposition thereto, during all the time there is no assurance to the contrary (Hobbes, [1651] 1968, p. 185-186).

A guerra refere-se, então, a batalhas verdadeiras assim como à falta de garantias de que o nosso adversário não nos atacará ou tentará nos prejudicar de alguma forma. Sem a possibilidade de entender a guerra nesse segundo sentido, como uma disposição para lutar, como poderíamos justificar algo como a Guerra Fria, que colocou adversários uns contra os outros sem que seus exércitos jamais tenham atirado um no outro? Nesse sentido, mesmo quando matar e morrer permanece dentro da estrutura de possibilidades do político, há "combates" políticos em que amigos e inimigos se avaliam mutuamente, sem que uma gota de sangue seja derramada.

A possibilidade de uma guerra sem matança, ou, mais precisamente, a ausência de uma relação causal entre "a disposição de lutar" e "a eliminação física" de adversários, é importante porque estende o escopo da reflexão de Schmitt sobre o político. Torna mais fácil desatrelá-la do âmbito das relações interestatais - onde ele julgou que ela fazia mais sentido - e aplicá-la ao cenário doméstico de oposições amigo-inimigo, sem necessariamente conduzir à guerra civil ou negar a força de tomada de decisão do Estado, como ele temia. Retomarei isso adiante.

Uma terceira forma de desviar a crítica e 
deixar de lado a interseção entre guerra e política consiste em seguir Chantal Mouffe e "higienizar" Schmitt, transmutando o antagonismo em agonismo e transformando inimigos que devem ser destruídos em adversários a serem confrontados (Mouffe, 1999, p. 4-5; 1993, p. 4). Isso deslocaria a referência à guerra para fazer com que o conceito schmittiano do político se adeque a pensar o dissenso legítimo e a política em formas de governo democráticas - especialmente as liberais -, em que supostamente reina seu "pluralismo agonístico. ${ }^{3}$ A suposição normativa de Mouffe sobre o tipo de inimigo e de conflito compatível com a democracia pluralista possui seu mérito, e muitos o endossam com satisfação, porém não é muito convincente nem particularmente útil.

Há duas razões para isso, talvez até mesmo três, se tivéssemos que pressionar Mouffe, perguntando-lhe como isso ocorrerá, como ela imagina o verdadeiro processo de transformar inimigos em adversários, ou antagonismo em agonismo, sem ter de apelar para um acordo voluntário, uma imposição oficial universal, ou uma idéia kantiana reguladora, como a que instrui a ética comunicativa de Habermas. Mas eu estou mais interessado em outros problemas. Um deles é que a proposta

${ }^{3}$ Uma possível fonte do "pluralismo agonístico" de Mouffe é o "respeito agonístico" de Connolly: nem puro combate (fosso), nem um modo de reconciliação (ponte), mas "uma ponte com um fosso" (Connolly, 1991, p.166167). Esse agonismo permite à autora definir o consenso democrático como um consenso conflitual. Para Mouffe, uma "liberal de esquerda" auto-intitulada (1999, p.5), “inimigo" é uma categoria restrita "àqueles que não aceitam as regras democráticas do jogo e, por esse meio, excluem-se da comunidade política” (1993, p.4), e antagonismo é uma "luta frontal entre inimigos que não têm fundamentos simbólicos comuns entre eles" (1999, p. 4-5). Inimizade e antagonismo são, portanto, inapropriados para a democracia pluralista, de modo que assumir o desafio de Schmitt significa transformar antagonismo em agonismo (p. 5) e inimigos em adversários que aderem aos princípios da democracia liberal. Contudo, ela é ambígua sobre o antagonismo. Algumas vezes, é uma condição quase transcendental de possibilidade e impossibilidade para a compreensão de democracia (1993, p. 8), e, por isso, é difícil ver como ou por que se pode transformá-la em agonismo sem destruir seu status quase transcendental. Em outras ocasiões, Mouffe a vê como um componente ontológico da política, que pode ser difundido mas não erradicado, mas ela não é sempre consistente nessa questão porque também fala do "potencial antagonístico presente nas relações humanas " (1999, p. 4, ênfase minha). Se o antagonismo pode ocorrer ou não, então ele não é um acessório, mas uma simples possibilidade da política. Dryzek (2005, p. 220-222) oferece uma crítica lúcida do pluralismo agonístico de Mouffe sob outro ângulo. para transformar inimigo em adversário não é verdadeiramente uma inovação, porque o próprio Schmitt tentou separar o seu conceito de inimizade da guerra - nem sempre com êxito, como acabamos de ver-distinguindo o inimigo político do inimigo mortal (Schmitt, [1938] 1972c, p. 196). Ele afina essa distinção em Theorie des Partisanen, especificando três tipos de inimigos (convencional, real e absoluto) e argumentando que apenas o terceiro fica fora do critério do político. Isso porque o inimigo absoluto não conhece limitações e, assim, percebe a guerra absoluta como sua correlata, enquanto Schmitt toma a inimizade relativizada do jus publicum Europaeum como modelo para seu inimigo político (Schmitt, 2007, p.88-90; 4 Slomp, 2007, p. 203-204, 209, para uma discussão dos três tipos de inimigo). Essa é uma maneira de evitar a sobreposição semântica entre a guerra e o político, ou de reduzir esse último a matar e morrer. Envolve a questão sobre que tipo de inimigo é aceitável e aproxima o entendimento de inimigo, de Schmitt, ao de adversário de Mouffe, contanto que o último não se transforme em mero competidor no mercado ou um questionador em assuntos intelectuais.

O segundo problema da leitura que Mouffe faz de Schmitt é que ela negligencia o fato de que identificar um opositor que não é nem um concorrente nem um questionador não constituía a última palavra de Schmitt sobre o político. Era apenas seu aspecto normativo: os grupos devem distinguir seus amigos de seus inimigos para contar como entidades políticas. Isso, para Schmitt, é completamente sem sentido sem o ângulo existencial, pois um grupo que identifica seus adversários, mas não está preparado para confrontá-los, de alguma maneira, não é um grupo político, definitivamente. As pessoas talvez balancem a cabeça em sinal de aprovação quando alguém diz que devemos estabelecer uma demarcação no caso do racismo. Éa coisa certa para dizer e fazer. Fazer, contudo, acaba sendo mais relevante do que dizer, porque coloca a questão sobre se algo implicará uma postura contra

${ }^{4}$ Há uma tradução para o português (Teoria da guerrilha), de Clarisse Tavares. Lisboa: Ed. Arcádia, 1975. 
o racismo baseada em princípios. Se aqueles que declaram opor-se ao racismo deixarem de protestar quando confrontados por ele, pode-se concluir que eles têm uma visão moral e ética das coisas, mas não que eles sejam políticos, no sentido schmittiano da palavra. Sem colocar o "risco existencial” na equação - isto é, sem a disposição para iniciar o ataque a opositores e a consciência de que fazer isso pode acarretar prejuízos adicionais - o apelo de Mouffe para substituir inimigos por adversários e o antagonismo por agonismo tornase uma solução inútil. Isso não decorre do fato de o "risco existencial" se aplicar apenas aos assuntos de vida e morte, pois, se fosse, a guerra seria mais uma vez a verdade do político, e todo o esforço para evitar a fusão da guerra com o político estaria fora de propósito. A remodelação sociológica da modernidade tardia como "sociedade de risco", como propõe Ulrich Beck (1992), mostra que o risco envolve a possibilidade de dano que poderia ou não levar à perda de uma vida. Mencionei algo sobre isso na discussão sobre hostilidade e sobre a visão hobbesiana da guerra. Seja em seu sentido restrito ou mais extenso, o risco existencial é inseparável do político e irredutível ao seu aspecto normativo.

Temos, então, três linhas possíveis de explicações para uma consideração belicosa do político: abandonar o critério de intensidade, ver a guerra como uma disposição para lutar e não simplesmente como uma batalha real, e, menos satisfatoriamente, transformar inimigos em adversários e optar por um critério normativo sem o complemento existencial. Nenhuma delas pode afastar inteiramente o receio de uma política puramente de adversidade e as conexões inquietantes entre cenários semelhantes àqueles da inimizade e da guerra encontrados na teoria política de Schmitt. Isso porque a guerra continua sendo uma situação extrema do político e, portanto, participa da estrutura de possibilidades desse último. Mas, na ausência de uma conexão causal entre a possibilidade da guerra e sua realidade, o desvio de uma para a outra não é regido por qualquer princípio de necessidade. Podemos ter inimizade sem guerra, situação na qual a consideração de Schmitt nos oferece, pelo menos, um critério referencial, "um arcabouço teórico para um problema incomensurável” (Schmitt, 1972a, p. 89), e não uma demonstração exaustiva, como ele próprio garantiu, do que se passa por política com ou sem derramamento de sangue.

Vale a pena observar que a distinção amigoinimigo possui traços de um paradoxo certamente produtivo em relação à amizade política: é que as mesmas oposições que colocam uns grupos contra outros também contribuem para unir uma coletividade. De um lado, a separação das pessoas, em campos "nós" e "eles", põe-nas juntas, ainda que apenas para confrontarem-se, de modo a se chegar a um acordo para reduzir tensões, ou para resolver suas controvérsias. Por outro lado, as divisões geram comunidades de amigos que inexistiam antes da designação de adversários e a disposição para confrontá-los. Um inimigo bem definido pode fornecer um sentido de propósito político para uma seleção de Estados, partidos ou movimentos e, de maneira oposta, a perda desse inimigo pode enfraquecer a compreensão de quem são eles e da causa pela qual estão lutando.

Basta simplesmente lembrar a desorientação entre os Estados ocidentais diante das consequências imediatas da Guerra Fria e da dissolução do Bloco Soviético. Eles sentiram alívio e alegria depois que seu principal inimigo, durante a maior parte do século XX, simplesmente debandou, mas também chegaram à conclusão de que o que os unia como uma comunidade de propósitos era, em parte, o medo do adversário. A aliança militar e política Organização do Tratado do Atlântico Norte (OTAN), criada para neutralizar a ameaça do Pacto de Varsóvia, ansiava por um inimigo bem definido para remodelar sua identidade e o sentido da sua missão. As coisas somente começaram a mudar quando uma ideologia de segurança, semelhante à hobbesiana, tomou conta do raciocínio governamental e da opinião pública após o 11 de setembro. Isso nos diz que o momento da vitória - considerando que a palavra vitória seja, aqui, adequada - pode ser tão solitário e desalentador como a 
"perda da perda" hegeliana, que Zizek descreve como "o padecimento de que nunca tivemos o que nós supostamente teríamos perdido" (1990, p. 252). O que nunca tivemos - o que jamais poderemos ter - é uma identidade política positiva ou puramente autorreferencial que floresce com a ausência de um inimigo. Os inimigos são nosso pharmakon; eles oscilam entre ser veneno ou cura, uma ameaça ao nosso modo de vida (ou, de forma menos dramática, um obstáculo ao nosso desejo de poder), ou algo que ajuda a nos tornarmos o que somos. Staten tem um nome para esse exterior paradoxal que participa da configuração do interior: ele o denomina exterior constitutivo (Staten, 1984, p. 15-19). Essa é a razão pela qual os inimigos não são um puro e simples momento de negatividade; eles funcionam como um exterior constitutivo, ao pôr em perigo nossa identidade, ao mesmo tempo em que promovem uma de suas condições de possibilidade. O ex-presidente dos Estados Unidos, Bill Clinton, exprimiu isso em termos mais práticos, ao dizer: "A dolorosa lição é que você define a si próprio por aquele a quem combate" (conforme citado em Bob Woodward, The Agenda). Em um sentido similar, Schmitt também entende que a política está baseada em como você se define em face do agrupamento amigo-inimigo.

\section{A DUPLA INSCRIÇÃO E A INTERMINÁVEL HISTÓRIA DAS FORMAS POLÍTICAS}

Podemos, agora, seguir adiante, explorando outras possibilidades que emergem do pensamento de Schmitt e trazê-lo para perto dos críticos contemporâneos do liberalismo e das inquietações das perspectivas pós-fundacionais. Já a primeira frase de O Conceito do Político é sintomática dessa proximidade. Ao dizer que "O conceito de Estado pressupõe o conceito do político”, Schmitt não está estabelecendo tanto a precedência causal do político como seu caráter excessivo em relação ao Estado. Ele está levando adiante o argumento que de alguma forma espelha a diferença ontológica em Heidegger e lembra a advertência de Lefort de que procuremos não confundir o político com seus modos de aparição históricos (Lefort, 1988, p. 11). Em troca, isso se encaixa na afirmação de Nietzsche sobre o excesso de tornar-se acima do ser, que Fink ([1960] 2003, p. 148-149) descreve como uma "ontologia negativa": não existem coisas em si mesmas, uma vez que "a existência objetiva", ou o ser, consiste numa domesticação temporária do interminável fluxo de tornar-se. De forma similar, o político, em Schmitt, sempre será excessivo visà-vis suas manifestações concretas, pois nenhuma esfera particular, assim como nenhuma forma histórica de política jamais esgotará as oposições amigo-inimigo. Isso se opõe aos esforços das tendências atuais do pensamento liberal-democrático do mainstream para incluir o político dentro das fronteiras das instituições estatais e dos partidos políticos. Podemos recorrer a Schmitt para expor essa questão como ideológica ou reducionista.

A primeira linha de $O$ Conceito do Político também condensa a conhecida distinção entre a política e o político, que eu introduzi sem determe numa discussão detalhada. Schmitt usa a política como um substantivo para indicar o lugar institucional da política. Pode referir-se ao Estado, como no caso do absolutismo e do sistema de Estado vestfaliano de um modo geral, ou à "esfera política” ou ao "subsistema político", expressões usadas para designar o lugar estatutário da política em democracias liberais. Em contraste, o referido artigo denota a forma nominal ou substantivada do adjetivo "político", que Schmitt usa para descrever uma classe de fenômenos independentemente de sua localização.

A teorização do "político" e de como ele transborda a política é a principal inovação de Schmitt. Como Lefort, ele se recusa a atrelar o político a um setor particular da vida; o liberalismo, ao contrário, não tem problemas para falar de várias esferas autônomas de atividade. Contudo o "político", em Schmitt, difere da maneira como Lefort concebe le politique, porque Schmitt não o vê como o princípio ou conjunto de princípios que moldam a sociedade ou realizam sua mise-en-forme, mas como um tipo de relacionamento no qual os 
grupos se interconectam como amigos ou inimigos. Diversamente da política, que tem um lugar próprio no sistema político ou subsistema, o político é inadequado, porque lhe falta um espaço próprio e, em princípio, pode aparecer em qualquer lugar. Para Schmitt, o político é indiferente em relação ao tipo de atores, ao objeto da disputa, à natureza da luta ou ao terreno do confronto, e é adicionalmente insensível à orientação democrática ou autoritária de uma determinada oposição. Não importa muito se os que desempenham o que Bobbio chama de atividade de agregar amigos e dispersar inimigos são partidos políticos, movimentos sociais, grupos de interesse ou Estados soberanos. É irrelevante se a atividade gira em torno de cargos eleitos ou do controle de um território, ou se ela se realiza no interior do ambiente institucional do sistema político, ou em espaços mais informais fora deste. Tudo o que importa, para Schmitt, é que as pessoas se agrupem com os amigos para enfrentar inimigos definidos. A definição não levanta tampouco a questão do escopo, se essas constelações supõem uma totalidade que abrange tudo, ou podem ocorrer em espaços descontínuos de uma micro-física política, mesmo quando ele gostaria que ela se aplicasse exclusivamente a Estados soberanos, portanto, a totalidades políticas convencionais (voltarei a isso na próxima seção). Schmitt admite estar certo que amigos possam, ao final, tornarem-se inimigos, e vice-versa, de modo que os reais contornos do político são inevitavelmente móveis, uma vez que eles acompanham o acaso mutante das oposições amigo-inimigo. Além disso, ele deseja remover do político uma origem e um telos, para cortar quaisquer conexões com um modelo e também com quaisquer leis presumidas de deslocamento da política, e posicionar, firmemente, a atividade política no terreno da contingência. Então, contrária à crença do fim da história, a dupla controvérsia (double bind) de Schmitt, como a de Lefort, indica que a relação entre o político e a política permanecerá ad infinitum e impedirá o primeiro de ser sequestrado por uma forma particular da última.

Duas conclusões, relativamente corretas, podem ser extraídas daí. Uma é que a especificidade do político não se refere à constituição de um novo domínio autônomo, mas a um tipo de relação - a relação amigo-inimigo - que pode surgir em qualquer lugar. A outra é que a política e o político são dois registros de matéria política: eles coexistem e se entrelaçam, mas não são redutíveis a um ou ao outro. Schmitt retorna a essa distinção muitos anos após a publicação de O Conceito do Político. No prefácio à edição italiana, ele escreve:

\begin{abstract}
O perfil clássico do Estado desapareceu quando diminuiu seu monopólio da política e uma diversidade de novos temas foram introduzidos na luta política, com ou sem referência ao Estado ou a um conteúdo "estatal" (Staatsgehabe). Isso marca a emergência de uma nova fase para o pensamento político. As pessoas começaram a distinguir a política do "político" e a questão dos novos condutores e novos objetos da realidade política se tornou gradualmente o tema central da complexa problemática do "político" em sua totalidade. Isto é, simultaneamente o ponto de partida e o significado de todos os esforços para distinguir os múltiplos novos temas do "político" que se tornam ativos na realidade política da política, quer seja uma realidade estatal ou não, originando novos tipos de agrupamentos "amigo-inimigo". [...] Nossa questão relacionada aos novos objetos da política - quer estatal ou não permanece: o critério do "político" que eu destaquei - a distinção entre amigos e inimigos - é de fato uma abordagem (Ansatz) que reconhece esta realidade política. (Schmitt, 1972b, p. 24-25).
\end{abstract}

Schmitt, obviamente, exagera a inovação dessa fase, pois a distinção entre a política e o político também se mantém no caso do Estado absolutista, embora indiretamente. Pode-se ver isso em seus próprios escritos. Ele afirma que, nos Estados europeus clássicos, havia uma identificação entre o "estatal” e o "político”, uma vez que apenas o Estado poderia tomar decisões políticas (basicamente para tratar outros Estados como amigos ou inimigos, ou permanecer neutro em conflitos entre outros Estados). O político, com suas divisões e oposições, foi banido do cenário doméstico, porque foi negada aos atores abaixo do nível governamental a possibilidade de identificar seus inimigos; apenas o Estado tinha autoridade para tomar decisões soberanas sobre essa matéria. Os conflitos entre os atores domésticos - intrigas palacianas, conspirações, rebeliões dos desconten- 
tes - eram simplesmente assuntos de ordem pública, sendo classificados como "desordens" a serem tratadas pela polícia (Schmitt, [1963] 1972a, p. 90-91). ${ }^{5}$ Schmitt admite que essas eram, algumas vezes, chamadas de "político", mas foi infeliz ao lhes aplicar o rótulo. Tal hesitação é um sintoma de outra tensão em seu pensamento. Derrida identifica-o muito bem e diz que Schmitt oscila entre o desejo de pureza conceitual e a consciência do status contestado de conceitos políticos (Derrida, 1997, p. 113-117). Isto é, ele faz uma distinção bem definida entre o político e o não-político (ou guerra e paz, combatente e civil, público e privado, e assim por diante), enquanto insiste que os conceitos políticos são polêmicos, de modo que sua efetiva valência está disponível a quem se interessar, e, portanto, não pode aspirar a uma pureza discursiva. Schmitt não pode tomá-la das duas maneiras.

A questão não é forçar uma escolha entre essas alternativas, ou procurar um terreno neutro consensual entre elas, mas observar a tensão que se desenvolve na maneira reservada de Schmitt de aceitar a persistência do político na ordem pacificada do Estado absolutista. Rebeliões, conspirações e outros distúrbios podem não ser o "político", no sentido schmittiano estrito do termo, mas são traços do político que nos lembram que aquilo que é determinado está sempre exposto a desafios e nunca é determinado inteiramente ou definitivamente. Não importa, de fato, se esses distúrbios constituem o retorno do reprimido, ou um aguilhão do fracasso do projeto absolutista para cumprir sua própria promessa de um domínio doméstico inteiramente pacificado. O que conta é que intrigas palacianas e rebeliões contradizem a pretensa anulação do político. O corolário é claro: o absolutismo é um formato de política que deseja circunscrever o político às relações amigo-inimigo entre Estados, mas logra apenas hegemonizá-las, porque não consegue banir essas relações do cenário doméstico.

Esse excesso do político sobre a política nos fornece um ângulo para introduzir o tema da du-

\footnotetext{
${ }^{5}$ Daí afirmação de Schmitt (1996b, p. 31) de que o Estado moderno, em seus primórdios, era mais caracterizado pela "polícia" do que pela "política".
}

pla controvérsia, ou da dupla inscrição, mencionado por Zizek. Na sua leitura de Lefort - o argumento também se aplica a Schmitt - a dimensão do político é duplamente inscrita: é tanto "um momento do Todo social, um entre seus subsistemas", como o próprio terreno no qual o Todo é decidido, "no qual o novo Pacto é planejado e construído" (Zizek, 1991, p. 193). Devemos ter precaução em relação a essa referência a um "Todo" capitalizado, porque ele sugere uma forte noção de totalidade em rixa com a dupla inscrição. Objetividade é um termo mais apropriado. Por essa razão, pode-se dizer simplesmente que o político inscreve-se como domínio enobrecido de intercâmbios políticos (a política) normalizados ou institucionais e como o negativismo de decisões e ações que coloca a objetividade em questão (o político), quer nos níveis macro ou local, dentro ou fora do subsistema político.

Há, contudo, dois mal-entendidos em relação à dupla inscrição. Um é a tentação para modelar a relação entre a política e o político em torno de algo como a distinção hobbesiana entre o estado civil e o estado de natureza, respectivamente, como se os termos se enfrentassem mutuamente numa relação de pura e simples exterioridade. Haveria, então, uma boa política, que se realiza em seu espaço de apresentação designado ou próprio, e uma política do político, perturbadora ou imprópria, que ameaça - ou poderia ameaçar - a civilidade da ordem instituída. O outro mal-entendido é a assimilação da política e do político à distinçãopadrão que os cientistas políticos fazem entre política do mainstream e política alternativa. Teríamos, então, algo como uma "política política" (political politics) do establishment e uma "política do político" (politics of political), de radicais que não podem operar com êxito no mainstream ou a quem não agrada a idéia de fazê-lo. Ambas as visões são enganadoras. A política e o político se interpenetram porque existe uma dupla codificação, e não dois códigos alternativos ou modos de inscrição.

A maioria dos argumentos sobre a interpenetração da política e do político refere-se a como o “político" está presente na "política”. É isso que 
Zizek tenta fazer quando fala da dupla inscrição. Precisamos mostrar que a recíproca também é verdadeira. Primeiramente, vou examinar como um negativismo do político permanece alojado na esfera política delimitada ou espaço enobrecido da política. Os intercâmbios no interior dos ambientes institucionais têm muito pouco em comum com a imagem embelezada da sociedade debatedora, onde o melhor argumento ganha o dia, e as regras permanecem intocadas pela discussão. Bem ao contrário, elas põem a objetividade à prova com bastante regularidade; o poder constituído retém uma capacidade constituinte porque a esfera polí tica é um local onde o negativismo - perturbação do estabelecido e a possibilidade de recriá-lo - não foi neutralizada ou banida, mas simplesmente enobrecida. Essa não é uma referência oblíqua à interpretação de Agamben do Estado de exceção Schmittiano como uma zona indistinguível entre poder constituinte e constituído. Tenho em mente algo muito mais corriqueiro, ou seja, que os legisladores mudam as leis e emendam a constituição, ou até mesmo criam uma nova, um voto de desconfiança derruba o governo, os cidadãos se engajam em desobediência civil ao recusar obedecer à lei, conflitos entre o executivo e o legislativo podem paralisar o andamento do governo, e assim por diante. Em parte, essa é a razão pela qual Foucault pode falar de política como a continuação da guerra por outros meios (Foucault, 1980, p. 16; mais completo em 2003); e Zizek diz que o negativismo nãoé uma exceção na passagem de uma positividade ou normalidade para outra, mas, em vez disso, que a própria normalidade é "o resultado", o "enobrecimento do excesso de negativismo esquecido" (1991, p. 195).

Se voltarmos nossa atenção agora para o político, veremos que a política também se entrelaça com ele. Podemos interpretar a argumentação de Schmitt de que o político é o status fundamental do homem como uma afirmação sobre a natureza humana, caso em que o político possui um status ontológico impermeável à modificação ou contaminação por um registro ôntico da política. Mas esse não precisa ser necessariamente o caso, ou pelo menos não deve ser apenas isso. Posso pensar em duas maneiras de conceber a presença da política no político, ou de alegar que o negativismo do político não é apenas negativismo. Uma é esboçada por Schmitt, quando diz que o inimigo absoluto ou ilimitado resulta de sua noção do político. Oinimigo é um adversário legítimo, até mesmo limitado em um combate, e, nesse caso, o inimigo é diferente, mas não totalmente diferente: é simplesmente outra coletividade belicosa e, portanto, também semelhante a nós (Schmitt, [1932] 1996a, p. 28). Ele também nos diz que um inimigo estrangeiro não é um criminoso. Por isso, as guerras podem ser limitadas e circunscritas através do direito internacional e podem terminar com um tratado de paz, que sempre inclui uma cláusula garantindo a anistia do derrotado, ou pelo menos sua proteção contra o abuso dos vencedores - ainda que esses últimos, muitas vezes, desconsiderem tais delicadezas pela forma como tratam os exércitos vencidos e a população civil dos países conquistados (Schmitt, 1972a, p. 92; vide também, 2007, p. 9). Essas referências ao reconhecimento de semelhanças com o adversário, à construção da inimizade no direito internacional e, de modo geral, à recusa para confundir inimigos políticos com inimigos mortais ou absolutos confirmam que o "político" nunca está em puro status naturalis, ou que sua natureza já é sempre parcialmente civilis.

Existe uma segunda maneira de identificar os traços da política no político. Gira em torno da própria idéia do político como uma possibilidade de agrupar pessoas conforme elas sejam amigos ou inimigos. A palavra-chave é "agrupar", a atividade de juntar um amigável "nós" e identificar aqueles que serão tratados como nossos adversários, o que nos diz imediatamente que os dois polos da distinção do político devem ser construídos e que ambos estão propensos a mudar continuamente. ${ }^{6}$ Essa dinâmica de criação e transformação é

${ }^{6}$ Isso é um paralelo ao que Kalyvas diz sobre o constituinte soberano, isto é, que "o poder constituinte aponta para os atributos de soberania, sejam coletivos, intersubjetivos e impessoais, para sua dimensão pública, cooperativa" (Kalyvas, 2005, p. 236). Ao nos lembrar que constituere ou constituir significa criar conjuntamente, ele está sugerindo que o poder soberano não é 
impensável sem formas de intercâmbio simbólicas e de outra natureza. Os laços de amizade se desenvolvem com o passar do tempo e envolvem relações de reciprocidade culturalmente mediadas, assim como investimento de sentimentos, especificação de interesses, obtenção de acordos, obrigações cumpridas e engajamento em polêmicas sobre como realizar tudo isso. Similarmente, identificar um inimigo requer toda sorte de representações para persuadir pessoas a tratar outro grupo como tal e incitá-las contra ele, se necessário. Aqueles que compartilham oposições amigo-inimigo fora do espaço enobrecido da esfera política - como as que envolvem movimentos sociais, sindicatos ou guerrilhas - e até mesmo como coalizões transnacionais apelam sempre para um discurso de direitos, quer invocando os direitos dos cidadãos, a universalidade dos direitos humanos ou "o direito a ter direitos" de Hannah Arendt. Se todos esses códigos simbólicos, culturais, legais e práticos permearem o político, então a conclusão é bastante óbvia: as convenções e instituições contaminam as oposições amigo-inimigo, mesmo quando essas ocorrem fora de seus espaços de manifestação, "próprios" ou designados.

Os schmittianos podem fazer objeções a isso e argumentam que a política não permeia o político, porque, uma vez que a oposição amigo-inimigo está estabelecida, todos os outros motivos (religiosos, morais, econômicos e assim por diante) desaparecem. O argumento não é convincente, porque se origina ou de uma confusão terminológica ou de uma afirmação pouco sincera. Tudo o que Schmitt diz a esse respeito é que, uma vez que se torna a constelação decisiva amigo-inimigo, "a antítese relevante deixa de ser puramente religiosa, moral ou econômica, e sim política" e, "precisamente no momento em que ela se torna política, põe de lado e subordina os seus critérios e motivos até aqui puramente religiosos, puramente econômicos, puramente culturais" (Schmitt, 1996a, p. 3, 38,

uma categoria ontológica que emerge de um éter metafísico, mas sim o resultado de esforços cooperativos não distintos daqueles envolvidos no artifício de criar amizades políticas. ênfase minha). Os termos que destaco em itálico são bastante eloquentes. Por um lado, se uma oposição não é mais puramente religiosa, porque se tornou política, é preciso aceitar que ela permaneça religiosa em algum âmbito, em vez de em nenhum. Em consequência, a pureza do político é um engodo, uma vez que o código supostamente autônomo traz a marca de uma hibridação precária. Shapiro nos ajuda a amparar essa reivindicação quando diz que a oposição amigo-inimigo de Schmitt é, de alguma forma, "parasita", porque extrai sua força de outras distinções e compromissos, não políticos (Shapiro, 2003, p. 107). Podemos identificar um parasitismo similar na afirmação de Schmitt de que todos os conceitos significativos do Estado são conceitos teológicos secularizados (Schmitt, [1922] 1985, p. 36)..$^{7}$ O que ele está dizendo é que esses conceitos seculares possuem uma marca teológica de nascença e, assim, não existe relação alguma de pura exterioridade entre eles. Essa é outra maneira de reconhecer que o político está impregnado por traços do não político. Por outro lado, se motivos não políticos isto é, religiosos, morais e outros - estão subordinados ao político, então eles tocarão o segundo violino para o político em vez de curvar-se elegantemente e abandonar a cena quando ele chega. Da mesma forma, ocorre com instituições e convenções: elas não são esteios silenciosos das constelações de amigo-inimigo, porque, em parte, as configuram. As formas e regras de compromisso-e, por implicação, a forma da amizade e da inimizade mudam, dependendo se a oposição política se desdobra em cenários autoritários ou democráticos, em guerras civis ou internacionais, em debates parlamentares ou nas ruas. Para ir diretamente ao ponto, a política contamina o político e reconfirma a afirmação sobre a double bind, codificação ou inscrição do político.

${ }^{7}$ Vide também a versão brasileira de Teologia política, traduzida por Elisete Antoniuk. Belo Horizonte: Ed. Del Rey, 2006. 


\section{FORMALISMO E REIVINDICAÇÃO NORMATIVA NO DECISIONISMO DE SCHMITT}

Esta é naturalmente uma visão entusiasmada da política, embora desalentadora. Schmitt ou está desinteressado em relação à emancipação, à justiça social e ao tratamento das injustiças em geral, ou vê tudo isso como ruídos inúteis, derivações retóricas daquilo que realmente importa, isto é, a gravidade do código amigo-inimigo. É também uma exposição algo formalista que o coloca bem próximo de endossar uma confrontação interminável, sem propósito ou cética, entre amigos e inimigos. A fórmula de oxímoro ${ }^{8}$ de "mudança invariável" descreve sua temporalidade. É invariável porque se baseia no código amigo-inimigo e, contudo, muda, seja porque os amigos de hoje podem ser os inimigos de amanhã, ou porque o político tem vários modos históricos de manifestação - Estados absolutistas e liberais democráticos, por exemplo, mas também guerras e revoluções - que modificam a maneira como a oposição amigo-inimigo se esgotará (Arditi, 1995, p. 24-25). Pode-se também dizer que o político é governado pelo que Deleuze descreve como "repetição" e Derrida chama de "lei de iterabilidade", o paradoxo da autoidentidade que incorpora um elemento diferencial sempre que ele é citado ou restabelecido. Schmitt adota esse sentido de repetição quando descreve a trajetória da modernidade européia do século XVII ao século XX como uma sucessão de esferas que funcionavam como matrizes de significados para as idéias, atividades e aspirações de cada século. Essas esferas foram sendo estruturadas em torno de diferentes preocupações, desde a moral teológica do século XVII às humanitárias, econômicas e técnicas dos séculos subsequentes, mas o que rege a sucessão de uma para a outra é o desejo de um domínio neutro e despolitizado que possa funcionar como um terreno onde conciliações possam ser alcançadas (Schmitt, [1929], 1993; também McCormick, 1993). Como todo desejo, esse nunca será satisfeito, porque, para Schmitt, o

${ }^{8}$ (N.T.): reunião de palavras aparentemente contraditórias. político é um elemento constitutivo da condição humana e retornará apesar de nossos melhores esforços para negá-lo, contê-lo, reprimi-lo ou neutralizá-lo. A história política pode não acabar, mas ela terá sempre um ressaibo de déjà vu.

Críticos, como Rancière, distanciam-se de Schmitt, em parte por essa razão. Como qualquer outro teórico, ele procura formalizar fenômenos políticos numa grade conceitual, mas, para ele, a política possui, de fato, um "conteúdo": a igualdade é sua medida, ainda que apareça apenas indiretamente através do tratamento da injustiça (Rancière, 2003; 1995, p. 173). A política é dissenso, a interrupção daquilo que é determinado pelas massas ruidosas ou parte daqueles que não têm participação na ordem existente (2001). Isso o distancia do formalismo de Schmitt, por colocar a sua compreensão de política sob a égide da emancipação. Uma forma de minar esse formalismo é dizer que as confrontações amigoinimigo possuem um referente situado. É qualquer coisa que esteja na posição de objeto de disputa (um cargo por eleição, o controle do território, a renúncia de um funcionário corrupto, a aprovação de uma lei, etc.). Isso rompe com a entropia da codificação puramente binária das relações amigoinimigo, introduzindo um terceiro excluído no cerne básico do político. Schmitt pode não ficar contente com essa solução, mas ela nos permite reter o esqueleto do seu conceito do político sem cair no formalismo. A referência ao terceiro excluído reforça nossa alegação sobre a dupla inscrição, porque é outra maneira de dizer que a política está também presente no político.

Outra opção é seguir Strauss [1932] (1995), um crítico do liberalismo igualmente conservador, que identificou um argumento normativo subjacente na versão do político de Schmitt. Enquanto Schmitt via o político como o status do homem, como a condição humana fundamental (Strauss, 1995, p. 99), Strauss mostrou que a busca de Schmitt pelo ponto de vista puramente político foi uma tentativa moral disfarçada. Baseou-se na crença da excelência do status quo sobre a insegurança de um estado de natureza caótico, e, assim, privilegiava 
decisões capazes de sustentar a ordem existente ou, no caso de essa última ser ameaçada, favorecia uma decisão capaz de restaurar a situação normal como um todo. A excelência da ordem era o julgamento moral não dito presente em seu trabalho. $\mathrm{O}$ desejo de ordem - de qualquer ordem, não importa de que tipo - é a ultima ratio ausente do seu raciocínio político. É por isso que ele propugna que o real objetivo da afirmação schmittiana do político (sua afirmação de que as oposições amigoinimigo não podem ser erradicadas) é menos uma polêmica com o liberalismo do que um esforço para justificar a necessidade moral de governo. Schmitt efetivamente procura advogar a demanda hobbesiana como uma instância capaz de proporcionar segurança, refreando a realidade conflitual do político, isto é, contendo nossa própria periculosidade e suprimindo os efeitos desagregadores do político sobre a ordem existente. Na análise final, diz Strauss, a afirmação do político de Schmitt contra o impulso liberal para negá-lo ou neutralizá-lo é uma asserção da moral e, portanto, acaba sendo uma forma invertida de liberalismo; liberalismo com uma polaridade oposta (Strauss, 1995, p. 113, 117).

O custo para rejeitar a acusação de formalismo seria adotar uma reivindicação moral: a excelência da ordem que garante segurança. Isso transforma Schmitt em um liberal disfarçado, um liberal escondido por conveniência. Outros o chamariam simplesmente de conservador, o que ele, de fato, era. Meier (1995) decifra muito da crítica de Strauss, sugerindo que Schmitt admitiu tacitamente que Strauss estava certo e que isso explica sua avaliação subsequente de Hobbes na (infame) edição de 1934 de O Conceito do Político. Aí Schmitt-então membro do partido nazista e Hitler já chanceler do Reich - adiciona o qualificativo oportunista "judeu" quando fala de um adversário intelectual como Harold Laski. Não é de estranhar que ele tenha escolhido usar a edição anterior de 1932, quando seu trabalho foi relançado na Alemanha em 1963. Naturalmente, é surpreendente identificar uma prescrição moral na arquitetura conceitual de alguém que nunca se cansou de exaltar as virtudes do decisionismo em sua polêmica com Kelsen e outros pensadores neokantianos durante a República de Weimar. Isso enfraquece a pureza do decisionismo de Schmitt, o que acaba sendo mais um problema para ele, que apreciava distinções bem definidas, do que para nós, que admitimos como natural que a contaminação esteja próxima de ser a regra. ${ }^{9}$ A consideração moral de seu raciocínio também vai mais além. Mostra que ele, como Hobbes e os liberais desprezados por este, desejava suprimir - ou, mais precisamente, no caso de Schmitt, conter - a força perturbadora do político, para superar a possibilidade do estado de natureza que, como Strauss descreve, é mais belicoso que inseguro (Strauss, 1995, p. 115).

A supressão do conflito não perturbou Hobbes, que, ao invocar a fábula de um estado de natureza original, endossou um jogo de soma zero entre o status naturalis e o status civilis, ou, pelo menos, pensou que tal cenário fosse desejável, apesar de não necessariamente alcançável. Para aqueles dentre nós que suspeitamos de rupturas sem resíduos, a crença de que se possa pôr um fim à insegurança tem um ressaibo de metafísica ou de meia verdade conveniente. Hobbes se abstém asperamente de propor tal ruptura. Isso por uma de duas razões: ou nós jamais renunciamos ao direito de autopreservação, em cujo caso a regra de qualquer soberano absoluto é inevitavelmente a regra $\mathrm{n}^{\mathrm{o}} 1$, ou a regra absolutista imperfeita, como era, ou porque nossa perigosa natureza humana não muda jamais e acabará por perturbar a ordem mais ajustada. De qualquer maneira, o Leviathan todo poderoso teria de ser um ornamento do esta-

${ }^{9} \mathrm{Na}$ verdade, o decisionismo puro está ausente também na versão schmittiana da política por outras razões. Vimos como afirmações normativas infiltram-se em seus argumentos sobre o político, seja quando ele nos pede para excluir inimigos absolutos ou quando argumenta que a natureza do político, do grupo, se apoia em sua capacidade de decidir por si próprio quem são seus amigos e seus inimigos (e então defender os primeiros e entrar em confronto com os últimos). Os comentaristas geralmente destacam a soberania da decisão sobre o inimigo. Quero chamar a atenção para o fato de que a distinção poderia romper com julgamentos de valor sobre o inimigo, mas nunca inteiramente, apenas porque nós sempre vemos nosso inimigo como egoísta e nós mesmos como parte justa e íntegra. Ver minha referência à afirmação de Shapiro sobre o aspecto "parasítico" do político vis-à-vis distinções não políticas no pensamento de Schmitt. 
do civil, se quisermos evitar uma retorno ao estado de natureza. Schmitt não endossa essa supressão abertamente, mas representa uma dupla face de rejeição e celebração de Hobbes. Ele afirma o político através da transmutação da guerra de todos contra todos na inevitabilidade das oposições de amigo-inimigo (uma estase pacífica é impensável), mas emparelha isso com uma meta não mencionada de contenção da insegurança do político através da ação de um governo forte, que funcione como shorthand para o Estado (um domínio pacificado é possível). Isso coloca o político em um registro cujo desejo de fechamento (a excelência da ordem em nome do refreamento do político) se sobrepõe aos esforços de Schmitt para desembaraçar-se dessa possibilidade através da teorização lúcida de uma dupla inscrição do político. Ele oscila continuamente entre essas posições, o que explica por que o real significado do significante "Schmitt” varia conforme se focalize o desejo de estabilidade ou excessividade do político e o que se faz com a tensão entre essas tendências em seu trabalho.

Essa ambivalência é mais notória com respeito ao Estado. Para colocar as coisas cruamente, seu raciocínio revela uma noção convencional de totalidade política que se sobrepõe ao território do Estado soberano, e de escopo que toma o Estado como o campo desejado de um objeto da política. Como vimos, ele reconhece a perda do monopólio do Estado sobre a política e a emergência de novos sujeitos da política, mas também lamenta o declínio da alta política do Estado-sistema vestfaliano e o tipo de certezas que o acompanhavam. Algo similar aconteceu com sua teorização da soberania. A visão de Schmitt evita a necessidade de um portador da soberania formalmente designado - o Estado, a classe, as pessoas. Ele faz isso afirmando que a soberania reside em qualquer um que possa decidir espontaneamente se a situação se tornou excepcional, e seja capaz de restaurar a normalidade, seja o Estado, um partido político ou um outro agrupamento. Isso significa que o local da soberania ou a determinação de quem é o portador da soberania não está fixado, mas é um efeito do jogo do político. Contudo Schmitt solapa essa versão situacional através de sua inclinação pelo Estado, como a unidade política decisiva. Sendo um crítico da neutralização liberal do político - os liberais adiam o momento da decisão empenhando-se numa discussão interminável -, ele queria restaurar a dignidade e a primazia do Estado. Estava, sem dúvida, afetado pelo sentimento de nostalgia em relação ao forte decisionismo que prevalecia nos tempos do jus publicum Europaeum, ou, mais provavelmente, entre os poucos Estados que tinham vontade e recursos para serem decisivos em seus assuntos (Brunkhorst, 2004, p. 515; Koskenniemi, 2004, p. 497). Os Estados tinham sido as unidades principais que se empenhavam na atividade de agregar amigos e combater inimigos, e ele acha desejável que eles permaneçam como unidades políticas que decidem, contanto que estabilizem o jogo político dentro de uma entidade governável. Novos sujeitos políticos podem operar em uma microfísica política conveniente, contanto que eles não discutam a primazia do macro-espaço do Estado.

\section{COM SCHMITT E APESAR DE SCHMITT}

Schmitt está querendo, então, admitir que a revolução democrática desferiu um grande golpe na pretensão de dotar a política com um objeto e (ou) modelo privilegiado. Contudo, ele vacila. Não está preparado para aceitar as consequências mais radicais que derivam daí, porque, na análise final, está relutante em abandonar o poder decisório dos Estados. Se ele tivesse feito isso, sua teorização do político teria se aproximado do que Derrida chama a "estruturalidade da estrutura", o reconhecimento de que o centro é parte do jogo da estrutura e não um referente transcendental que a governa de fora, como era (Derrida, 1993, p. 278-282). O Estado pode muito bem funcionar como o centro, mas, se o faz, isso é um efeito do jogo de forças, e não um privilégio estabelecido a priori - e, naturalmente, sua centralidade não o impede de ser também um local para o jogo das forças. Schmitt não ousa dar esse passo; ele deixa de aceitar a ausência 
de um terreno final do político e, consequentemente, perde a estruturalidade da estrutura política. Acaba por reconhecer e temer a contingência da objetividade resultante de uma controvérsia, o que, no final das contas, o torna um modernista reacionário, um revolucionário conservador do pensamento político, como Herf descreveu Schmitt juntamente com seus pares, como Jünger, Spengler e Sombart (Herf, 1981, p. 813).

Será que isso o torna um mero comentarista ou um êmulo contemporâneo de Hobbes? Schmitt certamente admira Hobbes, que ele descreve como "verdadeiramente um poderoso e sistemático pensador político” (1996a, p. 65). Já vimos que ambos afirmam a ameaça do homem ou a inevitabilidade das oposições amigo-inimigo; eles assim fazem para justificar a necessidade de governo, um governo que refreie a nossa periculosidade e, portanto, contenha os efeitos centrífugos do político. Eles também veem os tumultos domésticos não como uma memória aterrorizante de tempos passados, mas como uma possibilidade sempre presente que ameaça a ordem da política de dentro; a impossibilidade de fechamento (transcendental) é, assim, imanente. Entretanto, Schmitt difere de Hobbes, pelo menos em um aspecto. Seu estado da natureza reconhece inimigos assim como amigos. Então, em vez de uma guerra individualista de todos contra todos, onde há apenas inimigos, há uma "guerra” que põe grupos em confronto, coletivos organizados. Strauss foi o primeiro a observar isso. Hobbes concebe grupos organizados como Estados soberanos, mas o pensamento de Schmitt sobre o político não está restrito a esses agentes, porque, para ele, as constelações amigo-inimigo do político precedem o Estado e definem a condição humana.

Essa é uma diferença muito importante. Três consequências derivam dela. A primeira é que, se as oposições do político definem a condição humana, Schmitt tem de conceber grupos de amigos e inimigos como realidades pré-estatais. Ele admite isso, dizendo que o conceito do Estado pressupõe o do político; este último precede o Estado e é mais abrangente do que ele, o que significa que o Estado é uma forma ou fase histórica do político, entre outras, e não o seu momento culminante. A segunda é que, se isso for verdade, então Schmitt deve admitir também que há, ou pode haver, agrupamentos intraestatais como partidos políticos. $\mathrm{O}$ que ele faz quando fala da nova fase para o pensamento político na longa passagem citada anteriormente. E, uma vez que os partidos políticos se tornam parte do político, não há razão tampouco para excluir os movimentos sociais e outros grupos. Finalmente, por implicação, não existe nada nesse raciocínio que nos impeça de aplicá-lo a novos agrupamentos não estatais de amigos e inimigos que se estão desenvolvendo fora do território físico do Estado-nação. Ou seja, pode-se usar o critério do político de Schmitt para examinar a oposição política numa ordem pós-vestfaliana, quer entre Estados ou envolvendo atores que procuram modificar o ritmo e a direção de processos globais em uma posição diferenciada daquela do nível governamental.

A recusa em equacionar a política com o político e a concomitante reivindicação relacionada à ubiquidade e à desterritorialização das oposições amigo-inimigo abrem um caminho para pensar a política que não está restrito ao Estado soberano e está desonerado por uma forte noção de totalidade. Elas são o aspecto mais importante do trabalho de Schmitt que vale a pena manter e desenvolver, embora, como outras coisas em seus escritos, sempre numa direção que ele não imaginou possível seguir, ou simplesmente não quis seguir. Isso porque Schmitt, o admirador do sistema de Estado vestfaliano, percebia muito bem esse desenvolvimento, mas também buscava - ou pelo menos desejava - detê-lo. Para ele, as oposições amigo-inimigo tornaram-se um critério operacional tosco para identificar o político dentro ou fora de locais de manifestação designados como "oportunos", o que equivale claramente a uma admissão da "impropriedade" do político, que pode aparecer sem ser convidado, a qualquer momento, em qualquer lugar. Entretanto, ele lamenta isso, porque teme que possa vir a ser a eliminação do lugar privilegiado do Estado. Essa impropriedade equivale a uma democratização da decisão sobre a exce- 
ção, que ele temia. Isso explica os esforços de Schmitt para conter a disseminação do político. Ele o faz, como um caso de julgamento prático, quando encorajou o governo a invocar o Art.48 da Constituição de Weimar em 1932 para impedir o NSDAP (Partido Nacional-Socialista Alemão, em sua abreviatura original do alemão Nationalsozialistische Deutsche Arbeiterpartei) e o KPD (Partido Comunista Alemão, em suas siglas originais: Kommunistische Partei Deutschlands) de perturbar a soberania do Estado. Ele também propôs isso conceitualmente, quando procurou limitar a luta legítima de guerrilha ao tipo "telúrico" ou territorial que existia antes da luta ideológica planetária de guerrilha inaugurada por Lênin e Mao. ${ }^{10}$ Contudo, como foi mencionado, ao teorizar a impropriedade da política (a possibilidade de agrupamentos amigo-inimigo aparecerem em qualquer tempo e lugar), ele já nos fornece instrumentos conceituais para afrouxar os laços da camisa de força que ele gostaria de ter colocado em torno do político.

No cômputo geral, as vantagens da visão desterritorializada do político de Schmitt compensam as dificuldades que ela possa ter. Essa visão também nos proporciona uma fenda para uma olhada rápida sobre algo que vai além de uma mera semelhança entre seu pensamento e a asserção pósfundacional da estruturalidade da estrutura política, ainda que ele, no final das contas, retroceda quanto ao reconhecimento das últimas consequências disso.

Duas questões permanecem, e eu posso apenas mencioná-las sucintamente. Uma é se há ou pode haver algo entre amizade e inimizade, isto é, se esse critério básico é suficiente, ou necessita de algo mais para justificar desempenhos políticos que não são clara ou necessariamente classificáveis nesses termos. Gestos simbólicos, como uma marcha contra a corrupção na vida pública, uma vigília com velas acesas pelas vítimas do racismo, ou os Concertos Live 8 da campanha Make Poverty History podem ser considerados como políticos, sem identificar um inimigo particular ou levantar a possibilidade de guerra de qualquer

${ }^{10}$ Agradeço a Kam Shapiro por apontar a conexão com a Theorie des Partisanen. maneira óbvia. Aqueles que participam de tais ações são amigos, no sentido político de constituir uma comunidade de pessoas com idéias semelhantes, que defendem um modo de vida, mas não percebem necessariamente a política em termos de amigos e inimigos. O outro problema é como evitar um julgamento formalista de antagonismo, uma vez que minha proposta de que é preciso referir-se a um termo ausente (o terceiro excluído ou objeto de disputa) como um referente situacional para compromissos entre amigos e inimigos talvez seja apenas uma solução ad-hoc. Contudo, já é um começo.

Tradução: Licia Pedreira Revisão Técnica: Breno Bringel

(Recebido para publicação em outubro de 2008) (Aceito em dezembro de 2008)

\section{REFERÊNCIAS}

ARDITI, Benjamin. Tracing the political. Angelaki: Journal of Theoretical Humanities, Londres, Routledge, v. 1, n. 3 , p. 15-28, 1995

BECK, Ulrich. Risk society. Londres: Sage, 1992.

BOBBIO, Norberto. Política. In: ; MATTEUCCI Nicola; PASQUINO, Gianfranco (Ed.) Diccionario de política. Mexico: Siglo XXI, 1982. v. 2, p. 1240-1252.

BRUNKHORST, Hauke. The right to war: hegemonial geopolitics or civic Constitutionalism? Constellations: [S.l.], Blackwell Publishers, v. 11, n. 4, p. 512-526, 2004

CONNOLLY, William. Identity/difference. Democratic negotiations of political paradox. Ithaca, Nova York: Cornell University Press, 1991.

DERRIDA, Jacques. Structure, sign and play in the discourse of the human sciences In: Writing and difference. Londres: Routledge, [1966], 1993. p. 278-293.

$$
\text { Politics of friendship. Londres: Verso, } 1997 .
$$

DRYZEK, John. Deliberative democracy in divided societies. An alternative to agonism and analgesia. Political Theory, [S.l.], Sage, v. 33, n. 2, p. 218-242, 2005. Disponível em: http:// ptx.sagepub.com/ cgi/content/abstract/33/2/218

FINK, Eugen. Nietzsche's philosophy Londres: Continuum, [1960], 2003.

FOUCAULT, Michel. War is the Filigree of Peace. Oxford Literary Review, Oxford, v. 4, n. 2, p. 15-28, 1980.

Society must be defended: lectures at the Collège de France, 1975-1976. Nova York: Picador, 2003.

HERF, Jeffrey. Reactionary modernism. Some ideological 
origins of the primacy of politics in the third reich. Theory and Society, London, Sage, v. 10, n. 6, p. 805-832, 1981.

HOBBES, Thomas. Leviathan. Middlesex: Penguin Books, [1651]. 1968. (Ed. C.B. Macpherson).

KALYVAS, Andreas. Popular sovereignty, democracy, and the constituent power. Constellatio: International Journal of Critical and Democratic Theory, [S.l.], Blackwell Publishers, v. 12, n. 2, p. 223-244, 2005.

KOSKENNIEMI, Marti. International law as political theology: how to read nomos der erde? Constellations: International Journal of Critical and Democratic Theory, [S.l.], Blackwell Publishers, v. 11, n. 4, p. 492-511, 2004. LEFORT, Claude. Democracy and political theory. Cambridge: Polity Press, 1988.

McCORMICK, John. Introduction to Schmitt's “the age of neutralizations and depoliticizations". Telos. [S.l.], n. 96, p. 119-129, 1993.

MEIER, Heinrich. Carl Schmitt and Leo Strauss: the Hidden dialogue. Chicago: University of Chicago Press, 1995. Trad. J. Harvey Lomax.

MOUFFE, Chantal. The return of the political. Londres: Verso, 1993.

. The challenge of Carl Schmitt. Londres: Verso, 1999.

RANCIÈRE, Jacques. Post-democracy, politics and philosophy. Angelaki, Londres, v. 1, n. 3, p. 171-178, 1995. Interview.

. Ten theses on politics. Theory \& Event, [S.l.],The

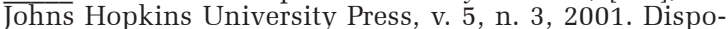
nível em: http://muse.jhu.edu/login?uri=/journals/ theory_and_event/ v005/5.3ranciere.html

.The thinking of dissensus: politics and aesthetics. In: CONFERENCE FIDELITY TO THE DISAGREEMENT: JACQUES RANCIERE AND THE POLITICAL, Londres. Goldsmiths College, 16-17 set., 2003.

SCHMITT, Carl. Premessa. In: MIGLIO, Gianfranco; SCHIERA, Paolo. Le categorie del 'político'. Bologna: Il Mulino [1963]. 1972a. p.89-100.
. Premessa all'edizione italiana. In: . Le categorie del 'político', 1972b. p. 21-26,

. Corollario 2: Sulla relazione intercorrente fra i concetti di guerra e di nemico. In: . Le categorie del 'político', Bologna, II Mulino, [1938]. 1972c. p.193-203.

. Political theology. Four chapters on the concept of sovereignty. Trad. George Schwab.Cambridge/ Massachusetts: MIT Press, [1922], 1985.

. The age of neutralizations and depoliticizations. Telos, [S.1.], v. 96, p. 130-142, [1929] 1993.

. The concept of the political. Trad. George Schwab. Chicago: University of Chicago Press, [1932] 1996a.

The Leviathan in the state theory of Thomas Hobbes. Meaning and failure of a political symbol. Trad. George Schwab.Westport, CT: Greenwood Press, [1938] 1996b.

. Theory of the partisan. Trad.r G. L. Ulmen. Nova York: Telos Press, 2007.

SHAPIRO, Kam. Sovereign nations, Carnal States. Ithaca: Cornell University Press, 2003.

SLOMP, Gabriella. Carl Schmitt on Friendship: polemics and diagnostics. Critical Review of International Social and Political Philosophy, Cambridge, Routledge, v. 10, n. 2, p. 199-213, 2007.

STATEN, Henry. Wittgenstein and Derrida. Lincoln/Londres: University of Nebraska Press, 1984.

STRAUSS, Leo. Notes on Carl Schmitt. The concept of the political In: MEIER, Heinrich. Carl Schmitt and Leo Strauss. The Hidden dialogue. Chicago: The University of Chicago Press, [1932], 1995. p. 91-119.

ZIZEK, Slavoj. Beyond Discourse Analysis. In: LACLAU, Ernesto. New reflections on the revolution of our time. Londres: Verso, 1990 p. 249-260.

. For they know not what they do. Londres: Verso, 1991. 


\section{ON "POLITICS": with Schmitt and in spite of Schmitt}

\author{
Benjamín Arditi
}

A standard observation in the literature is that Schmitt's take on the political wavers between nostalgia for the strong state of the Westphalian era and a lucid depiction of the new statal and non-statal political scene. What is less obvious is that tensions like this don't close off more interesting possibilities in his work. To find them one must be prepared to think with and despite Schmitt, either navigating through his theory of the political without endorsing all the consequences he draws from it or taking his reflection in directions he did not foresee or wish to go. I will look at some of the tensions - the nature of the link between war and politics, the status of enemies, the moral claim about the goodness of order - and use his distinction between politics and the political - perhaps his most original insight - to develop the theme of the double inscription of the political.

KEY wORDS: politics, political, post liberalism, Carl Schmitt, resistances.

\section{A PROPOS DU "POLITIQUE”: avec et malgré Schmitt}

\author{
Benjamín Arditi
}

L'une des observations standard dans la littérature est la manière qu'a Schmitt de traiter les oscillations politiques entre la nostalgie d'un Etat fort de l'ère westphalienne et une description lucide du nouveau scénario politique d'état ou non. Ce qui reste moins évident, c'est que ces tensions n'empêchent pas que des possibilités plus intéressantes surgissent de son travail. Pour les trouver, il faut s'entraîner à penser avec et malgré Schmitt, soit en navigant au travers de sa théorie du politique, sans en endosser toutes les conséquences, ou donner à ses réflexions des directions que lui-même n’a pas prévues ou alors n'a pas voulu prendre. Nous examinons quelques-unes des tensions - la nature du lien entre guerre et politique, le statut d'ennemis, la justification morale de l'excellence de l'ordre - et nous faisons usage de la distinction faite entre la politique et le politique - sans doute son discernement le plus original - afin de développer le thème de la double inscription du politique.

MoTS-CLÉs: la politique, le politique, post-libéralisme, Carl Schmitt, résistances.

Benjamín Arditi - Doutor em Teoria Política pela Universidade de Essex, Reino Unido. Professor de Ciência Política na Faculdade de Ciências Políticas e Sociais da UNAM, México. Foi professor na Universidade Federal de Santa Catarina (Brasil), Maryland (Estados Unidos) e no Instituto Mora (México). Suas linhas de pesquisa estão relacionadas com o pensamento continental, identidade e diferença, populismo e representação, o conceito do político, política pós-liberal, resistências globais e formas pós-hegemônicas da política. Entre as suas publicações recentes mais relevantes, estão: The Contingency of the Commonplace (New York, 1999), El reverso de la diferencia: Identidad y política (Caracas, 2000), ¿Democracia post-liberal? El espacio político de las asociaciones (Barcelona, 2005) e Polítics on the Edges of Liberalism: difference, populism, revolution, agitation (Edimburgo, 2007). 